\title{
Profiling Self-regulated Learning in Online Mathematics Teacher Training: A Case Study of a GeoGebra Course
}

\author{
Marfuah \\ PPPPTK Matematika, Sleman, Indonesia \\ marfuahmy@gmail.com
}

\begin{abstract}
Online training has now become an alternative means of delivering continuous professional development courses to improve teacher competencies. The benefits of online training are flexibility of access, cost efficiencies, ease of content updates, and uniformity of content. However, there are many aspects that determine if teachers can be successful in online training, and one is self-regulated learning. This study aims to profile self-regulated learning as case study in an online mathematics teacher training held by PPPPTK Matematika using GeoGebra. Using a survey method, this study describes the participants' self-regulated learning profile as they accomplished nine tasks in the GeoGebra course.
\end{abstract}

Keywords: online training, self-regulated learning, GeoGebra

\section{Introduction}

Educational change requires teachers to constantly improve their professionalism. As a profession, teaching cannot be separated from technology. There are many studies about the impact of technology on improving teaching and learning. Educational technology applications produce a positive effect on mathematics achievement (Cheung \& Slavin, 2013). Eisinger (2000) stated that by combining traditional learning characteristics with the unique environment available online, elements that emerge would reveal excellent e-learning, namely the sharing of knowledge. Currently, there are a lot of teachers who are familiar with computers and internet for accessing student learning media. However, teachers often ignore the utilization of information and communications technologies to improve their own competencies.

Applications and digital technologies enhancement in education has always been one priority of the Indonesian government. Therefore the Indonesian Ministry of Education and Culture through PPPPTK Matematika (Centre for Development and Empowerment of Mathematics Teachers and Education Personnel) facilitates mathematics teachers to improve their competencies as a route to their continued professional development. Many teacher courses have been implemented by PPPPTK Matematika through various modes. In 2015, one of the courses conducted was online training for mathematics teachers, including junior high school, senior high school, and vocational high school teachers.

There were many worries about how online training could produce effective change in teacher practice. Online training required participants to have positive self-regulated learning attitudes, beliefs, and abilities so that they could get the benefits of the training. Even though some essential abilities improve with age, self-regulated learning competency is neither 
automatic nor fast and it can be improved through suitable teaching and practice (Delfino, Dettori, \& Persico, 2011). Therefore, understanding self-regulated learning profile of the participants is an important issue.

\section{Online Training and Self-regulated Learning}

The Organization of Economic Co-operation and Development (OECD) defines professional development as:

\footnotetext{
... a body of systematic activities to prepare teachers for their job, including initial training, induction courses, in-service training, and continuous professional formation within school settings" (Burns, 2011).
}

Thus, with the large number of teachers in Indonesia, online training is being embraced by in-service programs as a route to teacher continued professional development. The Indonesian Central Bureau of Statistics (Badan Pusat Statistik) reported the number of teachers in Indonesia at the Ministry of Education and Culture as follows (Badan Pusat Statistik, 2016).

Table 1.

Number of Teachers in Indonesia

\begin{tabular}{|l|l|}
\hline Level & Number of Teachers \\
\hline Primary school & $1,539,819$ \\
\hline Junior high school & 596,089 \\
\hline Senior high school & 278,711 \\
\hline Vocational high school & 186,401 \\
\hline
\end{tabular}

This number represents a very large number compared to the ability of the government to facilitate teachers through conventional training. Therefore, the implementation of online training becomes a breakthrough that provides a massive solution, is more efficient, and overcomes geographical constraints (Perraton, 2002). Distance education has grown in significance as an educational tool just like technology has developed and progressed over the years. The $21^{\text {st }}$ century has seen rapid progress with such things as the internet and online learning (El-Seoud, Taj-Eddin, Seddiek, El-Khouly, \& Nosseir, 2014). Moreover, online training provides many benefits:

- flexibility of time and place;

- reduction of the cost required to put teachers and students in the same room;

- allows facilitators update the course material anytime so participants can access the latest material as soon as possible;

- participants can control the learning process themselves; 
- provides uniformity in content as each participant obtains the same subject matter, thus reducing the possibility of misinterpretation; and

- easier data management with greater capacities than traditional classroom learning.

However, this does not mean there are no weaknesses and challenges in the implementation of online training.

- Online training participants are required to have basic computer literacy skills. This becomes a challenge especially when teachers are not familiar with the internet.

- Internet network, bandwidth, reliable providers are primary needs in order to participate in online training. Unfortunately, there still are so many areas in Indonesia with a poor internet network.

- Online training requires a culture of self-regulated learning, the ability to learn independently. Success in the online training process highly depends on how the instructor in the training of participants fosters a culture of self-regulated learning.

- Although distance education provides cost-saving, online training providers must make a sizeable initial investment in the application, for the provision of infrastructure, design, and maintenance. Furthermore, the training participants are also expected to meet all of the costs arising from the online activities.

- Material deliveries that are less constructive hamper the transfer of knowledge through online training.

Among those challenges, self-regulated learning has an important role in determining the success of online training participants. According to Zimmerman (1990), self-regulated leaning involves three features: (1) their use of self-regulated learning strategies, (2) their responsiveness to self-oriented feedback about learning effectiveness, and (3) their interdependent motivational processes. Zimmerman defines three phases in self-regulated learning, they are planning, implementation, and reflection. Meanwhile, Zumbrunn, Tadlock, and Roberts (2011) described self-regulated learning as a process that assists persons in managing their thoughts, behaviors, and emotions in order to successfully navigate their learning experiences. Hence it can be concluded that self-regulated learning is a process whereby an individual fosters learning by himself/herself, including planning, implementation, and evaluating their learning objectives and progress in achievement. 


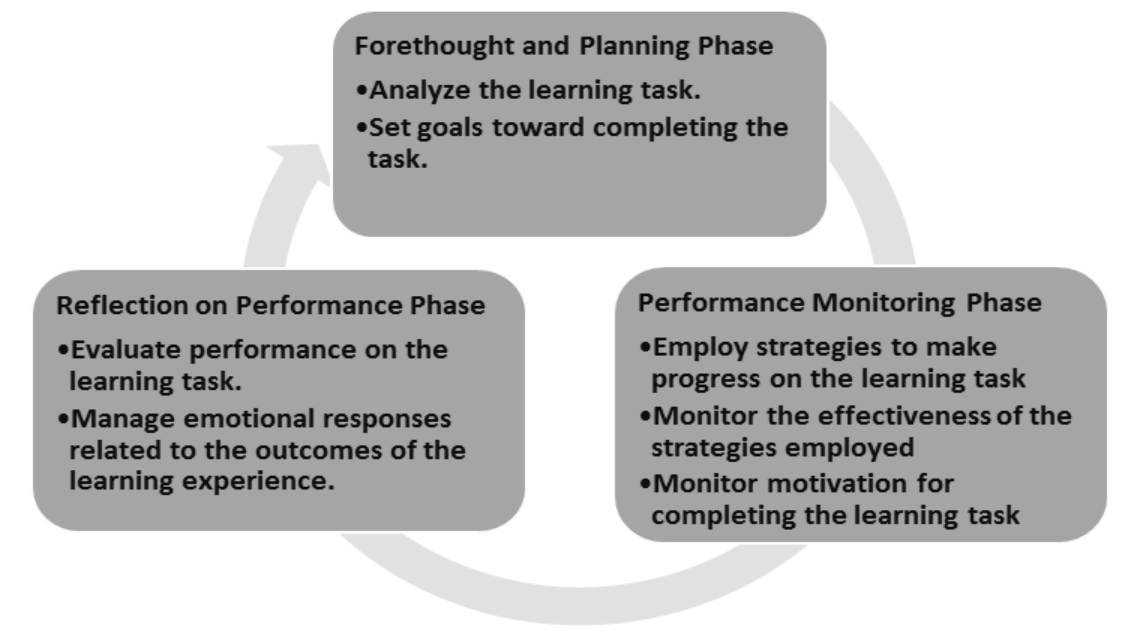

Figure 1. Phases of self-regulated learning (Zumbrunn, Tadlock, \& Roberts, 2011)

Self-regulation is not a mental ability or an academic performance skill, rather it is the self-directive process by which learners transform their mental abilities into academic skills (Zimmerman, 2002). According to Chen (2002), self-regulation is neither a measure of mental intelligence that is unchangeable after a certain point in life nor a personal characteristic that is genetically based or formed early in life. So, there are still options to continue developing self-regulation for any individual who wants to learn. Chen (2002) also cited Pintrich and Zimmerman's research reported that a learner with a high record of academic achievement is known to be better in implementing self-regulated learning than learners with a record of low learning achievement.

\section{Research Study}

The research study was carried out within a course designed and run for mathematics teacher training by PPPPTK Matematika in 2015. The course could be accessed online (http://diklatonline.p4tkmatematika.org/) with specific username and password. The course was based on the use of GeoGebra in the teaching and learning cycle in schools. The aim of the course was to acquaint the participants with GeoGebra as set of learning and teaching tools to improve teaching and learning through its use. It lasted for three-week. The participant cohort was segmented into virtual workgroups, each supported by two tutors. There were three big cohorts, each with 100 participants.

\section{Context and Methodology}

The aim of this study was to profile participants' self-regulated learning in online mathematics teacher training held by PPPPTK Matematika in 2015 using a GeoGebra course as a case study. A total of 219 teachers was the subjects of the study. Their background varied with regard to their gender, teaching experience, technology literacies, and levels of teaching.

During the course, nine tasks were sequentially proposed in three different discussion spaces created purposively. The tasks were: Basic GeoGebra (1-6), GeoGebra for Systems of 
Linear Equations topic (7), and GeoGebra for Geometry Transformation Topic (8-9). At the end of every task, the teachers were asked to respond to a simple questionnaire consisting of five item statements to profile their self-regulated learning.

Furthermore, the self-regulated learning to be surveyed in this study was restricted to three aspects which consist of motivation, strategies, and self-evaluation. For the strategy aspect, there were three strategies: allocating time for the sake of completing the task, finding another learning resource, and collaborating with other participants. The questionnaires were compiled using a Likert scale of 1-5, with 1 expressing high disagreement with the statement and 5 expressing very agreement with the statement.

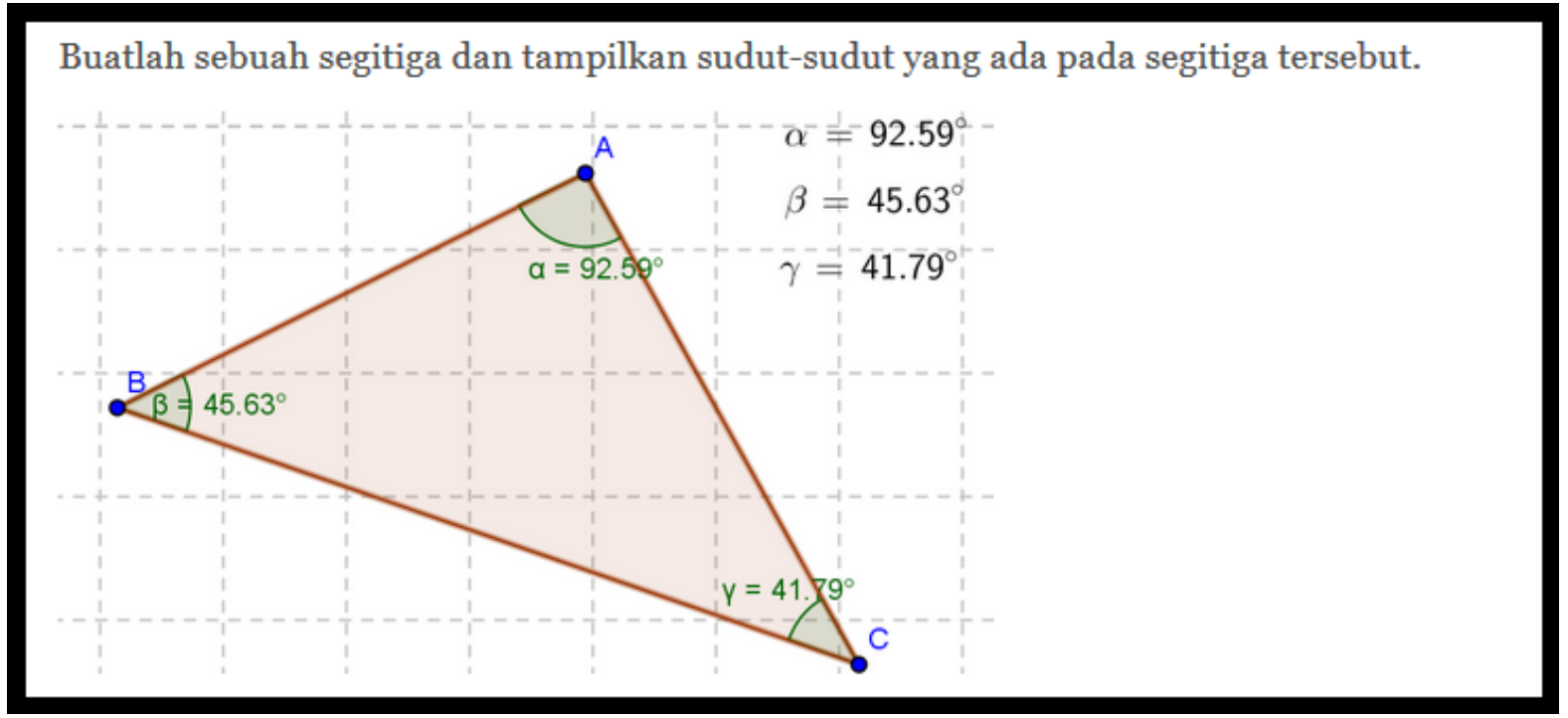

Figure 2. One of GeoGebra course tasks

\section{Results}

Statistical analysis was done to ensure that the questionnaire was valid and reliable. The mean and standard deviation for each scale were calculated to profile teachers' selfregulated learning. The value of Cronbach alpha scores for all five item statements was 0.65 which implies that the questionnaire was adequately good in measuring teachers' selfregulated learning with online training.

Overall, teachers had positive perspectives on all aspects of self-regulated learning measured. The highest mean score was motivation, which implies that teachers could already see the expected benefits of using GeoGebra as a dynamic software package for teaching mathematics. Out of 219 teachers, 73 teachers (33.3\%) said that they had zero knowledge about GeoGebra before participating in this course. So, it is understandable why the score on easiness was lower than the other. 
Table 2.

Average Item Mean and Standard Deviation Scores

\begin{tabular}{|l|l|l|l|l|l|}
\hline Task & Motivation & Strategies & Ease (self-evaluation) & Mean & STD \\
\hline Task 1 & 4.68 & 3.83 & 3.69 & 3.97 & 0.65 \\
\hline Task 2 & 4.67 & 3.81 & 3.42 & 3.89 & 0.64 \\
\hline Task 3 & 4.59 & 3.77 & 3.46 & 3.87 & 0.65 \\
\hline Task 4 & 4.70 & 3.85 & 3.48 & 3.94 & 0.64 \\
\hline Task 5 & 4.64 & 3.77 & 3.53 & 3.89 & 0.65 \\
\hline Task 6 & 4.65 & 3.76 & 3.44 & 3.88 & 0.63 \\
\hline Task 7 & 4.59 & 3.84 & 3.21 & 3.86 & 0.60 \\
\hline Task 8 & 4.57 & 3.77 & 3.33 & 3.84 & 0.67 \\
\hline Task 9 & 4.51 & 3.75 & 3.09 & 3.77 & 0.67 \\
\hline Mean & 4.62 & 3.79 & 3.41 & & \\
\hline
\end{tabular}

\section{Motivation}

Motivation is a critical factor that determines self-regulated learning. Motivation drives individuals to exert their best efforts to accomplished learning activities (Zumbrunn, Tadlock, \& Roberts, 2011). All motivation mean scores of the participants to complete the tasks were above 4 which was a 'Very Good' category.

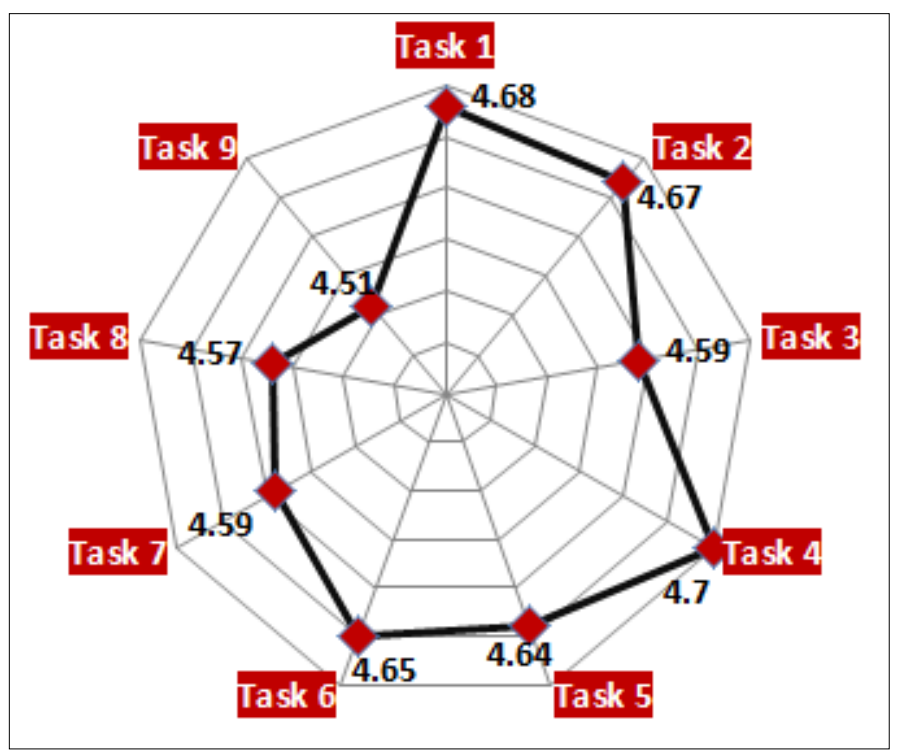

Figure 3. Motivation score diagram of GeoGebra course task

Highest motivation was when participants accomplished Task 4 (mean 4.70). Task 4 aims to draw simple triangle and its angles. A teacher said he was really helped with GeoGebra that he often draw such triangle to develop learning material. 


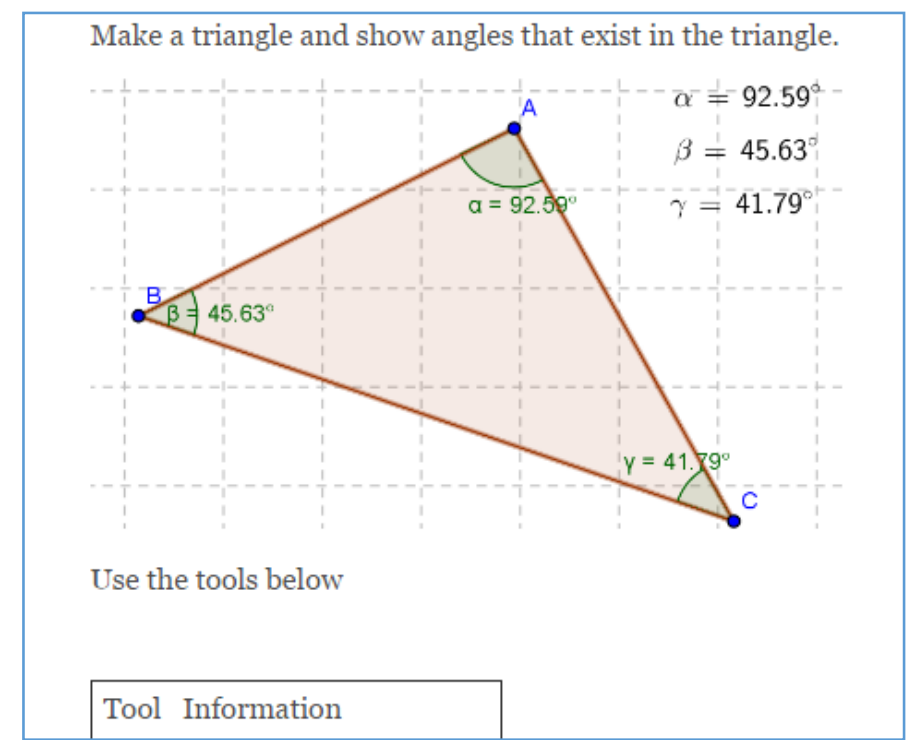

Figure 4. Task 4 in GeoGebra course (diklatonline.p4tkmatematika.org)

\section{Strategies}

As discussed above, there are three strategies of self-regulated learning measured in this study: (1) allocate time for the sake to complete the task, (2) find another learning resource, and (3) collaborate with other participants. All strategies mean score of the participants to complete the tasks were between 3 to 4 which means 'Good'. The result is shown in Figure 5 below.

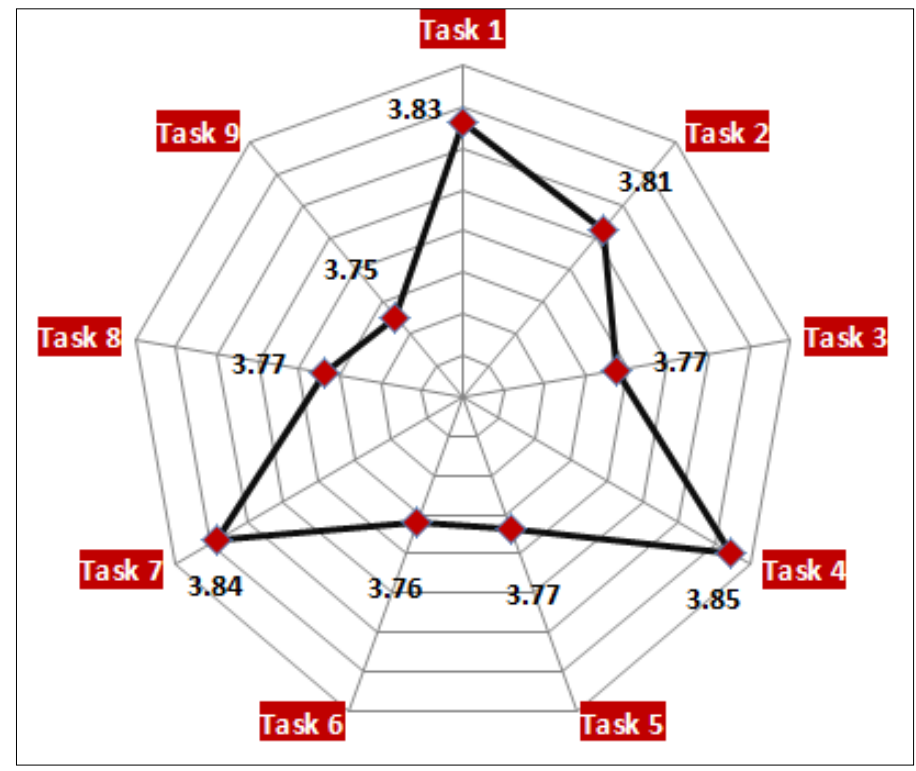

Figure 5. Strategy score diagram of GeoGebra course tasks

Time management involves scheduling, planning, and managing one's study time (Chen, 2002). An online environment does not only give benefits because the participant can learn anytime but the participant can also become neglectful through not planning their schedule. The tasks required learners to expand on the information presented in the course 
materials. These type of activities encourage the learners to be more self-directed as they reflect on their learning processes. Furthermore, participants could not only rely on the facilitators or reading material given. The online environment makes it easy for participants to seek other learning resources using search engines. Moreover, online training allows participants to develop social constructivism through discussion in the forums and chats. The groups were also provided with social media channels to facilitate the participants' discussions with other participants.

\section{Self-evaluation}

The last aspect of self-regulated learning of this survey was an evaluation. Delfino, et al., (2011) revealed that the self-regulated learning indicators for self-evaluation on computersupported collaborative learning included evaluation of cognitive and emotional aspects. This survey question was restricted to cognitive evaluation about level of ease of each task. When someone finds the material interesting but also finds it somewhat difficult to understand, it reminds him/her about needing a plan for better strategies to accomplish the tasks (Harris, Lindner, \& Pina, 2011). All the level of ease mean scores of the participants to complete the tasks were between 3 to 4 which was a 'Good' category. The higher the value of the response the easier the task according to the participants.

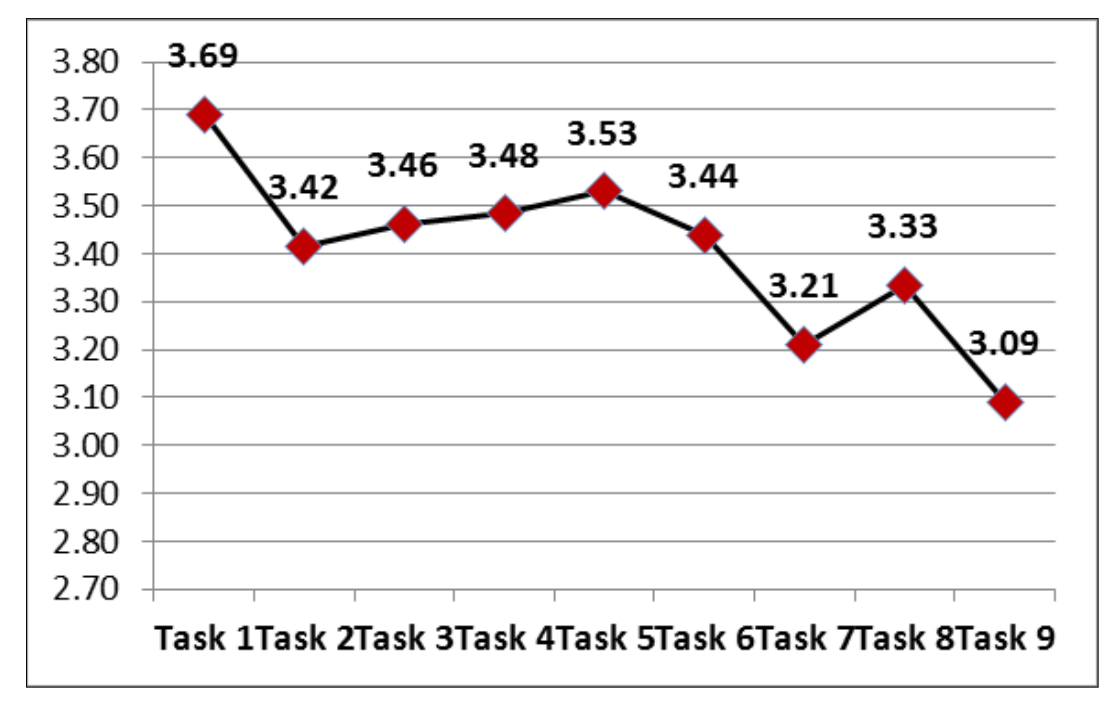

Figure 6. Ease score diagram of GeoGebra course tasks

Figure 6 shows that Task 1 was considered the easiest task according to participant responses and Task 9 was considered the most difficult. Task 1 was the easiest because it was the most basic for a beginner using GeoGebra. This task asks the participants to draw any objects using GeoGebra drawing tools. 


\section{Conclusion}

This study reviews the issue of understanding the nature of the tasks proposed in GeoGebra course and how they affect the way teachers practiced self-regulated learning during the activities carried out to accomplish the tasks. Almost 96\% teachers had positive self-regulated learning profiles during the GeoGebra course, which included motivation, strategies, and self-evaluation as shows in Figure 7.

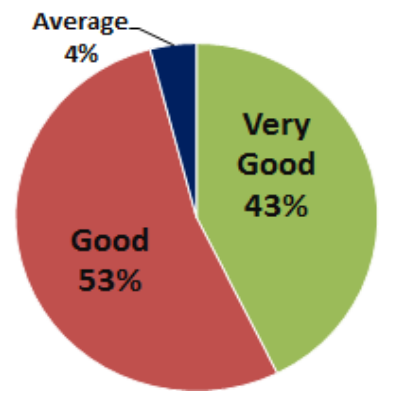

Figure 7. Diagram of teachers self-regulated learning profile

Out of three aspects of the self-regulated learning measure in this study, participants were scored 'Very Good' on motivation; on the other hand, they were scored 'Good' on the issues of processing strategies and self-evaluation.

While there were various obstacles for teachers to join online training, still they maintained the spirit to accomplish the tasks. Though the GeoGebra course is still not the ideal online training, nevertheless this study shows that these teachers were able to implement self-regulated learning as a means for teacher professional development.

As for the future, online training should be designed by considering self-regulated learning aspects. Online training should become a way to foster self-regulated learning for teacher's professional development. Positive self-regulated learning profiles will encourage teachers to give their best efforts in teaching and learning. Further research involving in-depth interviews is needed to increase our knowledge of how the various influences on selfregulation interact with each other.

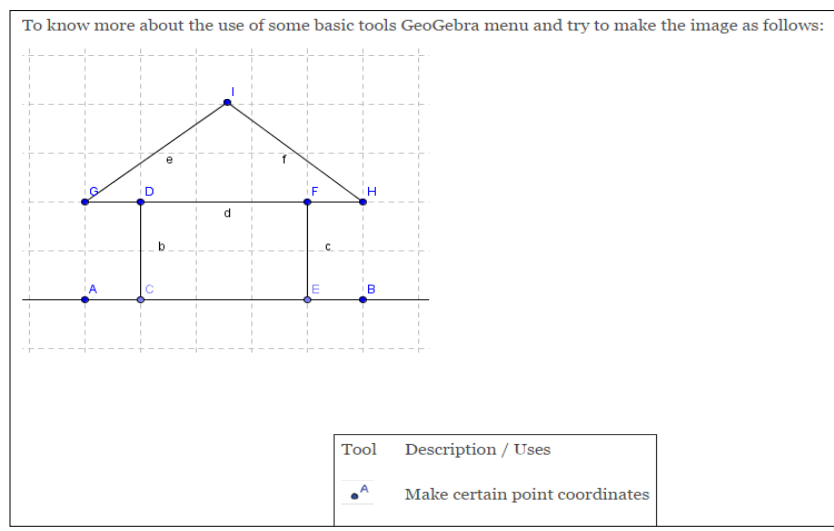

Figure 8. Task 1 in GeoGebra course (diklatonline.p4tkmatematika.org) 
Task 9 was about creating learning media object using GeoGebra to teach students about rotation with non $\mathrm{O}(0,0)$ as the center of rotation. Task 9 might be the most difficult for participants because they have to use their previous knowledge from previous tasks and no examples are given in the course materials.

Make learning media for rotation material by utilizing a slider (read module KB.2 part rotation). Use the rotary axes in addition to $(0.0)$.

Save the image in PNG format and upload it on this forum.

Figure 9. Task 9 in GeoGebra course (diklatonline.p4tkmatematika.org)

Overall participants' self-regulated learning profiles can be seen in Table 3.

Table 3.

Participants' Self-regulated Learning Profile

\begin{tabular}{|l|l|l|l|}
\hline Self-regulated Learning Category & Score & Frequency & $\%$ \\
\hline Very Good & $180 \leq$ score $\leq 225$ & 93 & 42.46 \\
\hline Good & $135 \leq$ score $<180$ & 116 & 52.96 \\
\hline Average & $90 \leq$ score $<135$ & 9 & 4.10 \\
\hline Poor & $45 \leq$ score $<90$ & 0 & 0 \\
\hline
\end{tabular}

Out of 219 teachers, 93 teachers (42.46\%) were in 'Very Good' criteria, 116 teachers (52.96\%) belonged to 'Good' criteria, while only 9 teachers $(4.10 \%)$ were in 'Average' criteria of implementing self-regulated learning. There was no participant with 'Poor' selfregulated learning given the fact that participants sign up for online training in PPPPTK Matematika through their personal initiatives.

\section{References}

Badan Pusat Statistik. (2016). Retrieved from https://www.bps.go.id/Subjek/view/id/28\#subjekViewTab3|accordion-daftar-subjek1

Burns, M. (2011). Distance education for teacher training: modes, models, and methods. Wasihington DC: Education Development Center, Inc.

Chen, C. S. (2002). Self-regulated learning strategies and achievement in an introduction to information systems course. Information Technology, Learning, and Performance Journal, 20(1), 11-25.

Cheung, A. C., \& Slavin, R. E. (2013). The effectiveness of educational technology applications for enhancing mathematics achievement in k-12 classrooms: A metaanalysis. Educational Research Review, 9, 88-113. 
Delfino, M., Dettori, G., \&Persico, D. (2011). Influence of task nature on learner selfregulation in online activities. In G. Dettori, \& D. Persico, Fostering self-regulated learning through ICT (pp. 145-161). New York: IGI-Global.

Eisinger (2000) A Framework for e-learning as a tool for knowledge management. Industrial Management and Data System, 102, 371-380.

El-Seoud, M. S., Taj-Eddin, I. A., Seddiek, N., El-Khouly, M. M., \& Nosseir, A. (2014). Elearning and students' motivation: A research study on the effect of e-learning on higher education. International Journal of Emerging Technologies in Learning (iJET), 20-26.

Harris , B. R., Lindner, W. R., \& Pina, A. A. (2011). Strategies to promote self-regulated learning in online environments. In G. Dettori, \& D. Persico, Fostering self-regulated learning through ICT (pp. 121-144). New York: IGI-Global.

Perraton, H. (2002). Distance education for teacher training. New York: Taylor and Francis Group.

Zimmerman, B. J. (1990). Self-regulated learning and academic achievement: An overview. Educational Psychologist, 25(1), 3-17.

Zimmerman, B. J. (2002). Becoming a self-regulated learner: An overview. Theory into Practice, 41(2), 64-70.

Zumbrunn, S., Tadlock, J., \& Roberts, E. D. (2011). Encouraging self-regulated learning in the classroom: A review of the literature. Metropolitan Educational Research Consortium (MERC). VA: Virginia Commonwealth University. 
Southeast Asian Mathematics Education Journal 2017, Vol. 7 No. 1 